\title{
Commission 22: Meteors, Meteorites \& Interplanetary Dust
}

\author{
PRESIDENT: Ingrid Mann \\ VICE-PRESIDENT: Pavel Spurný \\ ORGANIZING COMMITTEE: Jack Baggaley (NZ), Jiří Borovička \\ (Czech Republic), Pavel Spurný (Czech Republic), J. Watanabe \\ (Japan), I.P. Williams (UK), Vladimír Porubčan (Slovakia), \\ Peter Jeniskens (USA), and Monica Grady (UK)
}

\section{Meetings}

There have been three international meetings where the subject area of the meeting was to significant extent within the area of interest of commission 22 . These were:

\subsection{Meteoroids 2004 held in London Ontario}

. The Meteoroids 2004 Conference was held at the University of Western Ontario in London, Canada from August 15 to 21, 2004. This conference was the fifth in a series of meteoroid meetings which have been held approximately every three years since 1992, the previous one being in Kiruna, Sweden in 2001. Ingrid Mann chaired a scientific organizing committee which set the program for the conference. The meeting brought together scientists from more than twenty countries, to deliver 84 oral and 38 poster presentations. The papers represented the research contributions of more than 150 different scientists.

The conference provided a comprehensive overview of leading edge research on topics ranging from the dynamics, sources and distribution of meteoroids, their chemistry and their physical processes in the interplanetary medium and the Earths atmosphere, and space and laboratory studies of meteorites, micrometeorites and interplanetary dust were also well represented.

It was clear from the conference that the coordinated international campaigns for the Leonid showers provided a rich observational dataset and lead to the development of new observational and analysis techniques. Another trend obvious at the conference was the increasing use of sophisticated large aperture radars for meteor studies. High performance computing facilitates both dynamical model calculations and sophisticated ablation models. Significant progress was reported on ablation models for meteoroids ranging from dust to those producing bright fireballs. Study of solid particles entering the solar system from interstellar space and improved dust measuring capabilities on interplanetary spacecraft are an important research area which links astrophysical dust with solar system dust.

The majority of papers presented at the conference (a total of 69 papers) are being published as a special issue of the journal Earth, Moon, and Planets (Vol. 95, Nos. 1-4) and also in the form of an associated book published by Springer: Modern Meteor Science: An Interdisciplinary View which was edited by R.Hawkes, I. Mann and P. Brown (ISBN 1-4020-4374-0). The book will be accompanied by a CD-ROM which includes a selection of conference photographs and the complete abstracts of all papers from the conference.

As is reflected in the title of the spin-off book, this field is becoming increasingly interdisciplinary in nature, with researchers from astronomy, astrophysics, space science, 
space engineering, cosmochemistry, atmospheric science and geophysics, as well as others, now contributing to research in the field.

\subsection{ACM 2005 held in Rio de Janeiro}

. The proceedings of this meeting will appear both in a CUP book and a special Issue of Earth Moon and Planets. Though the main interest of this meeting was in Comets, Asteroids and TNO, significant time was devoted to meteor matters, in particular their inter-relations with other objects, in particular near earth objects and comets.

\subsection{Dust 2005 held in Hawaii}

Since all of these meetings contained published reviews of most aspects of the work of commission 22, we will not provide a full review of the subject area here and mention only a few highlights.

\section{Meteor streams and their parent bodies}

Perhaps the most noteworthy development has been the identification of asteroid like parents to a number of streams. In particular, the identification by Jenniskens (2004) of $2003 \mathrm{EH} 1$ as the parent of the Quadrantids led to speculation that this might be a remnant of a comet seen in 1491 (Williams et al, 2004) and a number of further papers published in the proceedings of the Meteoroids 2004 conference.

\section{Fireballs and meteor spectroscopy (P. Spurný and J. Borovička)}

The most significant achievement in observation of bright meteors since the previous IAU Report is the complete description of four meteorites falls based on instrumental data. It almost doubled our information about these rare natural events. The very detailed and complex description of the Moravka meteorites fall (H5-6 ordinary chondrites) in the Czech Republic is given in the set of four papers of Borovička et al. (2003a, 2003b), Borovička \& Kalenda (2003) and Brown et al. (2003). The most important achievement of the European Fireball Network (EN), which continued in systematic operation at more than 20 stations in the Czech Republic, Germany and Slovakia, was photographing of the Neuschwanstein meteorite fall on April 6, 2002. As it is shown in Spurný et al. (2002, 2003), Oberst et al. (2004) and Wimmer (2004), three rare EL6 enstatite chondrites were found in the computed impact area on the basis of these photographic observations. Acoustic, infrasonic and seismic analysis of the Neuschwanstein bolide is given in ReVelle et al. (2004). The importance of this unique and well-documented case is enhanced by the very close orbital similarity with the Příbram meteorites fall, the first ever instrumentally documented meteorite fall in history (Spurný et al. 2003). Another exceptional EN bolide, the deepest ever photographed fireball with hundreds of kilograms terminal mass is described in Spurný and Porubčan (2002). The orbit, atmospheric trajectory, entry dynamic and initial mass of the Park Forrest meteorite (L5), which occurred over Chicago suburbs, USA on March 27, 2003, is presented in Brown et al. (2004). This study is based on ground-based videographers, satellite systems and infrasound, seismic and acoustic records. The last instrumentally recorded meteorite fall, the Villalbeto de la Peña meteorite (L6), occurred over northern Spain on January 4, 2004. Its orbit, atmospheric trajectory, entry dynamic and impact area were reconstructed on the basis of one casual videorecord and several photographs and are described in set of papers of Trigo-Rodríguez et al. $(2004,2005)$ and Llorca et al. (2005). The flux of small near-Earth 
objects colliding with the Earth based on satellite records of bolide detonations in the atmosphere over the past 8.5 years is shown in Brown et al. (2002). New fragmentation model of meteoroid motion, mass loss and radiation in the atmosphere was designed by Ceplecha and ReVelle (2005). This very complex model is a breakthrough in the understanding of bolides and their dynamical and luminous behavior. Detailed study of very precise data on EN270200 fireball using this model is given in Spurný and Ceplecha (2005).

Borovička et al. (2005) presented a survey of video spectra of faint sporadic meteors and identified three populations of meteoroids without sodium. Trigo-Rodríguez et al. (2003, 2004, 2005) and Borovička (2005) derived elemental abundances in bright photographic fireballs. Kasuga et al. $(2005 \mathrm{a}, \mathrm{b})$ did the same for video spectra of a Leonid and a Geminid. Carbary et a. (2003) presented the first far-ultraviolet spectrum of a meteor and detected atomic carbon lines for the first time. Jenniskens \& Mandell (2004) discussed the origin of hydrogen in meteor spectra. The search for CN in Leonid spectra was unsuccessful (Jenniskens et al. 2004a) but two systems of $\mathrm{N}_{2}^{+}$were found (Jenniskens et al. 2004b, Abe et al. 2005a). Temperatures of air plasma in meteors were studied by Jenniskenns et al. (2004c). Schaefer \& Fegley (2005) applied an vaporization model to the ablation of meteoroids. Jenniskens et al. (2004d) presented a meteor spectrum obtained serendipitously at the ESO Very Large Telescope. Other meteor spectra were presented e.g. by Zender et al. (2002) and Jenniskens (2003). The interpretation of a June Bootid spectrum by Kasuga et al. (2004) was incorrect because of neglecting ionization. Jenniskens (2004) discussed current issues of meteor chemistry.

Borovička \& Koten (2003) identified three phases in the evolution of Leonid meteor trains, including a phase driven by atomic recombination. Further observation of the recombination phase are given in Spurný et al. (2005). High resolution spectra of meteor trains in the same phase were obtained by Suzuki (2003). Abe et al. (2005b) obtained spectra of meteor trains in the 300-930 nm range and were able to compute train temperature using the shape of $\mathrm{O}_{2}$ bands.

\section{References}

Abe, S., Ebizuka, N., Yano H. et al. 2005a, ApJ 618, L141

Abe, S., Ebizuka, N., Murayama, H. et al. 2005b, Earth, Moon \& Planets, in press (Meteoroids 2004)

Borovička, J. 2005, Earth, Moon \& Planets, in press (Meteoroids 2004)

Borovička, J. and Kalenda, P. 2003, Meteoritics Planet. Sci. 38, 1023

Borovička, J. \& Koten, P. 2003, ISAS SP-15, 165 (Leonid MAC Conf. 2002)

Borovička, J., Spurný, P., Kalenda, P., and Tagliaferri, E. 2003a, Meteoritics Planet. Sci. 38, 975

Borovička, J., Weber, H. W., Jopek, T., et al. 2003b, Meteoritics Planet. Sci. 38

Borovička, J., Koten, P., Spurný, P. et al. 2005, Icarus 174, 15

Brown, P., Pack, D., Edwards, W. N., et al. 2004, Meteoritics Planet. Sci. 39, 1781

Brown, P., Spalding, R. E., ReVelle, D. O. et al. 2002, Nature 420, 294

Carbary, J.F., Morrison, D., Romick, G.J. et al. 2003, Icarus 161, 223

Ceplecha, Z. \& ReVelle, D. O. 2005, Meteoritics Planet. Sci. 40, 35

Jenniskens, P. 2003, ISAS SP-15, 189 (Leonid MAC Conf. 2002)

Jenniskens, P. 2004, Adv. Space Res. 33, 1444

Jenniskens, P. 2004,AJ, 127, 3018

Jenniskens, P. \& Mandell, A.M. 2004, Astrobiology 4, 123

Jenniskens, P., Schaller, E.L., Laux, C.O. et al. 2004a, Astrobiology 4, 67

Jenniskens, P., Laux, C.O. \& Schaller, E.L. 2004b, Astrobiology 4, 109

Jenniskens, P., Laux, C.O. \& Wilson, M.A. 2004c, Astrobiology 4, 81 
Jenniskens, P., Jehin, E., Cabanac, R.A. et al. 2004d, Meteorit. Planet. Sci. 39, 609

Kasuga, T., Watanabe, J., Ebizuka, N. et al. 2004, A\&A 424, L35

Kasuga, T., Yamamoto, T., Watanabe, J. et al. 2005a, A\&A 435, 341

Kasuga, T., Watanabe, J. \& Ebizuka, N. 2005b, A\&A 438, L17

Llorca, J., Trigo-Rodriguez, J. M., Ortiz, J. L., et al. 2005, Meteoritics Planet. Sci. (in Press)

Oberst, J., Heinlein, D., Kohler, U. \& Spurný, P., 2004, Meteoritics Planet. Sci. 39, 1627

ReVelle, D. O., Brown, P. \& Spurný, P., 2004, Meteoritics Planet. Sci. 39, 1605

Schaefer, L. \& Fegley Jr., B. 2005, Earth, Moon \& Planets, (in Press)

Spurný, P., Borovička, J. \& Koten, P. 2005, Earth, Moon \& Planets, (in Press)

Spurný, P. \& Ceplecha, Z., 2005, Earth, Moon \& Planets, (in Press)

Spurný, P., Heinlein, D. \& Oberst, J. 2002, ESA SP-500, 137

Spurný, P., Oberst, J. \& Heinlein, D. 2003, Nature 423, 151

Spurný, P. \& Porubčan, V., 2002, ESA SP-500, 269

Suzuki, S. 2003, ISAS SP-15, 175 (Leonid MAC Conf. 2002)

Trigo-Rodriguez, J. M., Borovicka, J., Spurny, P., et al. 2005, Meteoritics Planet. Sci. (in Press)

Trigo-Rodriguez, J.M., Llorca, J., Borovička, J. et al. 2003, Meteorit. Planet. Sci. 38, 1283

Trigo-Rodríguez J.M., Llorca, J., Borovička, J. et al. 2005, Earth, Moon \& Planets, (in Press)

Trigo-Rodríguez, J.M., Llorca, J. \& Fabregat, J. 2004, MNRAS 348, 802, erratum MNRAS 350, 1152

Trigo-Rodriguez, J. M., Llorca, J., Ortiz, J. L., et al. 2004, Meteoritics Planet. Sci. Abs. 39, 5085

Williams, I.P, Ryabova G.O., Bauturin, A.P. \& Chernitsov A.M., 2004, MNRAS, 355, 1171

Wimmer K., 2003, Spectrum der Wissenschaft, Nov. 2003, 80

Zender, J.J., Witasse, O., Koschny, D.V. et al. 2002, ESA-SP 500, 121 (ACM 2002)

Ingrid Mann and Pavel Spurny President/Vice President of the Commission 